\title{
DEVELOPING CULTURAL SENSITIVITY: A STUDENT'S PERSPECTIVE
}

\author{
Annemiek VAN BOEIJEN ${ }^{1}$, Marieke SONNEVELD ${ }^{1}$, Chen HAO ${ }^{1}$ and Yassaman \\ KHODADADEH ${ }^{2}$ \\ ${ }^{1}$ Delft University of Technology \\ ${ }^{2}$ University of Tehran
}

\begin{abstract}
Cultural sensitivity is an important issue in design and not only about dealing with cultural diversity, but also about designing for cultural dilemmas that are related to multi-cultural contexts. This paper is concerned with cultural sensitivity and presents students' perspectives, which were obtained through workshops. For this aim at first workshops on cultural sensitivity in design were briefly introduced. Then the last workshop, which was performed in Kish Island (Iran) at University of Tehran, was explained and some design results were presented through illustration. 70 design students with different backgrounds and nationalities participated. In order to obtain the students' perspectives, an online questionnaire was sent to them. The mix of open and closed questions was related to students' learning experiences. The results were categorised into five themes that arose from the open questions. The findings indicate that students had a fruitful experience in the workshop and obtained a large amount of knowledge and experience regarding cultural sensitivity, not only through the workshop approach and teaching style, but also through the international character and its socials aspects.
\end{abstract}

\section{Keywords: Culture sensitivity, design education, international design workshops, design methods}

\section{INTRODUCTION}

Our globalised world, with interconnected societies and with a complexity of multicultural subgroups, confronts designers with the challenge of facing cultural diversity in their design process. On the one hand, this challenge may be experienced as 'a problem to be tackled', as a challenge to avoid cultural mistakes, such as Nike showed when developing sneakers with some Arabic decorations, inadvertently meaning the word 'Allah', thereby offending a large community of Islamic culture. On the other hand, and this would be our position, the challenge of becoming culture sensitive as designers is a positive attitude towards cultural diversity, seeing it as a rich source of inspiration for new concepts and for intercultural connection [1]. Being culture sensitive designers includes being aware of the cultural aspects of their designs, of their way of designing and of themselves as designers. Moreover, culture sensitive designers are not only aware of the cultural dimensions of design (in all aspects), they know how to integrate these cultural dimensions into the practice of their designing, while staying in tune with their own cultural beliefs and values. Thereby, cultural sensitivity in designing is not merely about understanding cultural differences, but more important about unfolding cultural dilemmas and finding the common grounds to build up on. Cultural sensitivity in designing is about building the cultural chasms or bridges through design [2]. Cultural sensitivity is developed through exposure to cultural differences [3], by working in multi-cultural contexts, and by facing the dilemmas that are raised within those contexts.

In a previous study, insights in how to develop cultural sensitivity were described from an educational and methodological point of view, by reflecting on our experiences with different educational settings learning styles [4], addressing cultural sensitivity in design [1]. These reflections were elaborated on from the teacher's perspective: our observations and interpretations of what was happening. However, these insights need to be completed with the reflections of the students themselves, to obtain a solid ground for further development of the educational initiatives.

This paper will address the development of cultural sensitivity in the courses we offer, from the perspective of the design students. How did they experience the design education initiatives that are 
focused on developing their cultural sensitivity? How did they phrase what they have learned? How did they experience the way they learned? And what could we, as teachers, learn from their experiences to improve design education aimed at developing cultural sensitivity, for example according to the six stages defined by Bennett [5]; denial, defence, minimisation, acceptation, adaptation, and integration. Up to date, we developed 5 one-week international workshops on cultural sensitivity, 3 in Shanghai (China), 1 in Wuxi (China) and 1 in Kish (Iran). All workshops had the same learning objective and structure. However, the workshops differed in context and in focus: awareness of one's own culture through self-observation; awareness of subcultures involving participants; company cultures; and awareness of cultural encounters between cultures.

The workshops needed to be evaluated on several outcomes, such as the lessons learned about cultural sensitivity in designing, and in the long run the integration of these learnings into the students' design practice. Next, it is valuable to evaluate the set up and the structure of the workshop itself.

In this study, the students of the workshop in Iran were asked to reflect on this second aspect: their experience of the workshop, not only regarding tools and methods that were offered, but also regarding the way the workshop was organised (structure, education style, timing, and so on).

This paper will first briefly introduce the workshop on culture sensitivity in design, illustrated with some design results from the workshop. Next, the reflections of the students will be presented along different themes that emerged from the reflections of the students. The paper will conclude with recommendations for further implementation of cultural sensitivity in design education.

\section{WORKSHOPS ON CULTURAL SENSITIVITY}

Our workshops on cultural sensitivity in design have a Design for Experience approach, evolving around a specific theme, such as 'social encounters on campus', 'elderly and food', or 'caring for clothes'. The one-week workshops follow a step-by-step approach, where every step is defined by a specific deliverable (figure 1): Collecting data about the context; creating a Cultura [6]; creating a Persona; generating user-insights; formulating a design goal and a design vision; creating a storyboard of the desired experience; and finally developing the design concept. Previous to the workshop the students are sensitised by little tasks to perform, such as small interviews with relatives, self-reflections or going on a photo safari. Throughout the workshop students are encouraged to go outside and engage with potential users. The students work in groups of 4 to 5 students, and on several occasions the groups give feedback on each other's work. Overall, this offers lectures on the topics and introductions to tools and methods in the mornings, after which the actual design projects are carried out in afternoon design sessions. The workshops concluded with final presentations and exhibition structured along the different deliverables. Figure 2 shows three examples of final designs.

\begin{tabular}{|c|c|c|c|c|c|c|c|c|c|}
\hline Phases & Prepare & kick-off & Discover & & & Develop & Deliver & Present & Evaluate \& Publish \\
\hline Time & 4-week & Day 0 & Day 1 & Day 2 & Day 3 & Day 4 & Day 5 & Day 6 & 3-month \\
\hline Activities & Sensitizing & $\begin{array}{c}\text { Mini- } \\
\text { Symposium }\end{array}$ & $\begin{array}{l}\text { Lecture } \\
\text { Session }\end{array}$ & $\begin{array}{l}\text { Lecture } \\
\text { Session }\end{array}$ & $\begin{array}{l}\text { Lecture } \\
\text { Session }\end{array}$ & $\begin{array}{l}\text { Lecture } \\
\text { Session }\end{array}$ & $\begin{array}{l}\text { Lecture } \\
\text { Session }\end{array}$ & $\begin{array}{l}\text { Exhibition } \\
\text { Ceremony }\end{array}$ & Survey \\
\hline $\begin{array}{l}\text { Methods } \\
\text { \& tools }\end{array}$ & 33 & & $\begin{array}{c}\text { Photo safari } \\
\text { Actor maps } \\
\text { Cardset }\end{array}$ & Cultura & Personas & 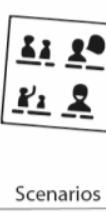 & Prototyping & Certificates & \\
\hline Deliverables & & & $\begin{array}{l}\text { Contextual } \\
\text { insights }\end{array}$ & $\begin{array}{l}\text { Contextual } \\
\text { insights }\end{array}$ & $\begin{array}{l}\text { Design } \\
\text { goals }\end{array}$ & $\begin{array}{l}\text { Design } \\
\text { concepts }\end{array}$ & Mock-ups & $\begin{array}{l}\text { Final } \\
\text { Designs }\end{array}$ & $\begin{array}{c}\text { E\&PDE Paper } \\
\text { Workshop Booklets }\end{array}$ \\
\hline $\begin{array}{l}\text { Social } \\
\text { events }\end{array}$ & & & & & & & & & \\
\hline
\end{tabular}

Figure 1. An overview of our workshop approach

\subsection{The Workshop for the International University of Teheran in Kish Island}

The workshop on Culture Sensitivity in Design developed for the International University of Teheran in Kish Island was culturally diverse in several ways: the participants as well as the team of design teachers were a mix of different nationalities with different design backgrounds. Next, the theme of the workshop specifically addressed cultural diversity on Kish Island: how could design improve the tourist experience of Kish Island, for example the cultural encounters between tourists and local communities? 
In all, 70 students (64 Iranian from different regions in Iran, 5 Chinese and 1 German) participated, divided in 14 groups, supervised by 4 design teachers.

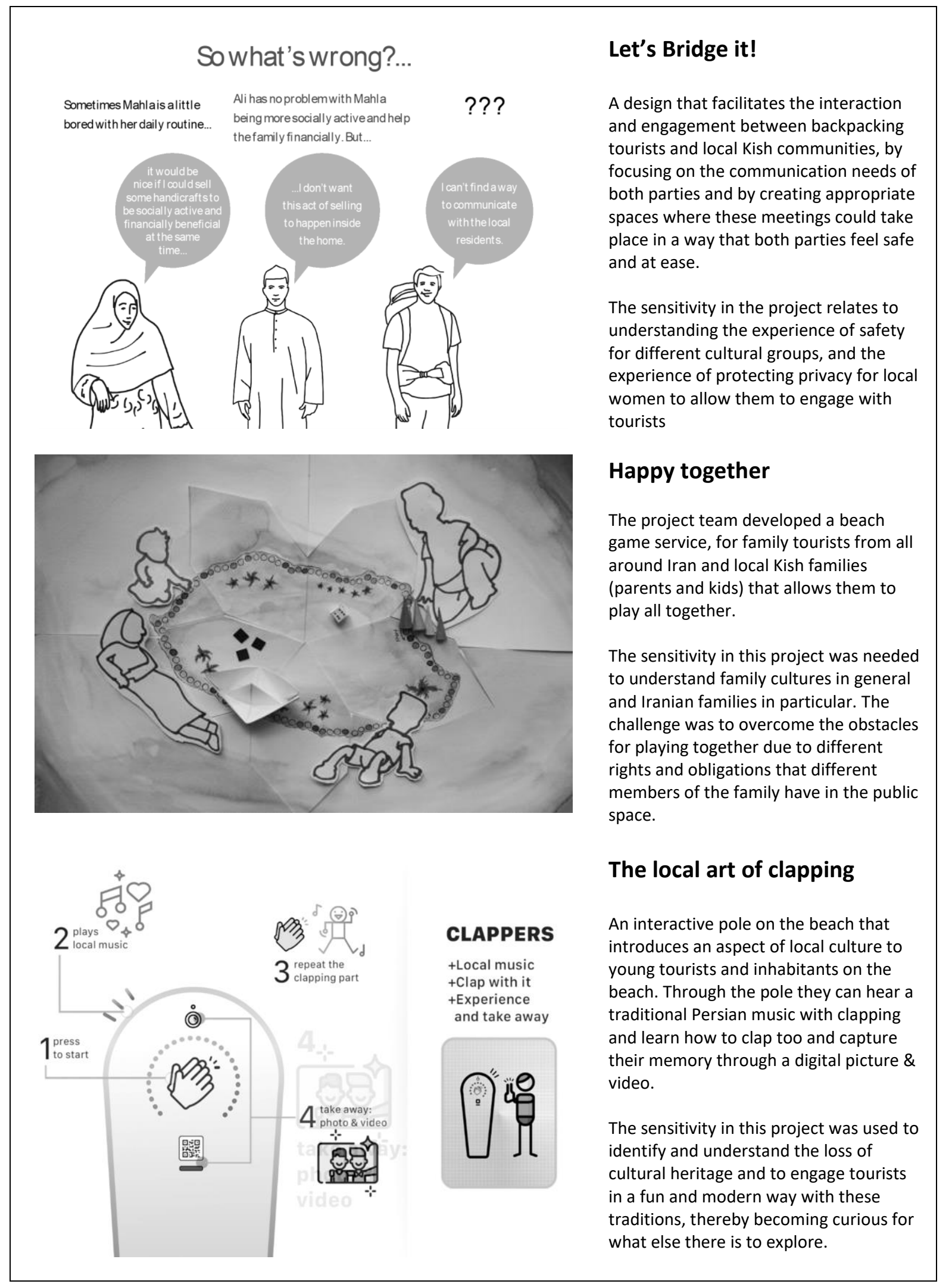

Figure 2. Three out of fourteen examples of project results 


\section{THE STUDENTS' PERSPECTIVES}

The students received an online questionnaire one month after the workshop, to reflect on their learning experiences. The questionnaire was a mix of open and closed questions, with 5-point scales for students to quantify their experiences.

The main reasons for participants to join the design event were the topic, learn new methods and tools, learn from well-known foreign institute, and learn from different people and institutes.

From the 70 participants 28 responded (40\%); one with a German, one with a Chinese and 26 with an Iranian background. The results (narratives) were clustered into themes and discussed in the team (the authors). The average overall score of the workshop (between 1 and 10) of the participants is 8.25 and without one participant who was very negative (scored 1 ) it is 8.75 , for which we conclude that the participants who filled in the questionnaire were very satisfied. For the difficulty level the majority (86\%) answered that it was about right ( 2 indicated that it was too easy, 1 far too easy, and 1 far too difficult). For the amount of work the majority (68\%) answered that it was about right (1 indicated that it was far too little, 3 too little, and 5 too much). This again presented a positive perception of the experience. In the following, the results are presented according to the themes that emerged from the open questions in the questionnaire. The themes are described and illustrated with quotes from the students. This section concludes with a discussion of the results and a reflection on the evaluation method.

\subsection{The experience of the international setting and the 'outsiders' role}

The responses show that our role as being outsiders - not only because of our different passport cultures and national cultural backgrounds, but also because of our representation of another (credible and wellknown) design institute - appeared to be an important reason for the participants to join. It opens up to new worlds and to new networks, as one of the students stated:

'Well, I wanted to have a wise vision on design at first, then I found out that you were coming from one of the best design universities. I really loved it and like to find an opportunity to work on it more.'

Experiencing being an 'outsider' as a student is also experienced as a pre to dive into the topic of the workshop: 'Because we all came from other cities for the workshop, we are somehow outsiders, like tourists in Kish, so we can see the problems easier and designing for Kish Island is mostly the best idea.' Students indicated that an important benefit of this design event was to meet other, new people: from different cultural backgrounds, from different design schools, and levels of education. The design teams were very mixed in terms of background and experience. Again, this was a challenge and some mentioned difficulties regarding teamwork, but it was mostly experienced as positive: 'It was my first time to be in an international workshop, so I learnt a lot from working with students from other countries as colleagues.' And: 'I had a great team work experience in the way I haven't experienced before. I loved the way I could communicate with the teachers and I'm thankful for the way they taught me to communicate with people from different cultures.' However, this seems to work best when there is enough diversity: 'I think it would be better if the number of foreign students were more.'

\subsection{The experience of a positive educational culture}

The ways teachers interacted with students was a positive surprise to most respondents. Students were used to teachers criticising their work in order to make them improve it and were now faced with the opposite approach: teachers seeking for the positive, to improve from there on. 'Teachers were full of energy and their communication with students was great. Also, they were so sensitive about it'. This positivity-and-open-eye-o-the-masters approach was experienced as very motivating and lowered thresholds to communicate: 'We were really comfortable approaching them and asking our questions.' This positive mind-set was experienced as consistent throughout the different activities of the workshop; not only during the workshop itself but also during the social events: 'The thing that surprised me was our mentors' behaviour were really amazing, we could talk with them easily, we went out and cycling in the beach, they sang for us, etc. Really, I was amazed how these professors can be nice and great.'. Positivity might be experienced as not critical enough, not serious, but the students seem to have experienced the right balance: 'It was enough friendly and enough serious'. However, each teacher supervised her own groups of students and to some this decreased the opportunity to experience different interaction styles: 'Dividing teachers among groups was a barrier to learn from all of them and know their different way of looking to the project.' Nevertheless, the curiosity for the different teaching styles prevailed: 'I believe the most valuable thing that I was learning throughout the workshop was seeing 
how our instructors (as experienced designers) were looking at the subject, how they instruct us to apply the methods we already know of, how they were steering our projects with their insightful comments, at which point they would say it is enough with research and give us the permission to move on to the next stage, what do they emphasis on, which projects do they actually relate to and why?, what is more important: going into details or telling a great story?

\subsection{The experience of time pressure to digest what culture is}

Several students commented on the time factor. The workshop was experienced as very intense, with many different tools and techniques to work with. Yet it seemed the workshop did not allow for enough time to engage with all of it properly, to understand and digest everything. 'I think the hours of being in workshop was a bit tense...' and 'Some [parts] of the process were a bit difficult at the first point, we couldn't understand it but after we got through it, we find it easier... or when our mentor explained it. Also, working in an unfamiliar language was experienced as adding to the need for more tie: 'and maybe the language was making some troubles, beside'.

In addition, the workshop seemed much focussed on the content itself, and didn't seem to provide enough leisure time: time to get to know each other and to discover the island. 'May be a bit more time or little smaller groups. Also, more time to ourselves to hang out in Kish Island.' Some suggested to make the workshop longer.

\subsection{The experience of working with methods and tools for culture sensitivity}

The workshop offered a step-by-step approach. In each step different design methods and tools (such as sensitising tasks, Cultura, the Crossing Cultural Chasm card set, storyboard and so on) were introduced to support the design process. Some participants mentioned that in the beginning it was hard to get the overview, to understand this rather comprehensive approach, and how to use the provided methods and tools. However, eventually for most students the insights fell into place, stating that 'Card set and Cultura were very valuable and helpful, particularly for providing a clear path and direction in moving toward the design goal.' And students could relate them to the goal of the workshop, as one participant stated: 'Personas and Storyboard were very valuable because they were in close contact with culture'. However, the students did not equally appreciate them all. Each student seemed to pick out his or her own new favourite. For some: 'Finding a good scenario was the tricky task, but it was interesting, and I think it was the most important part of the workshop.' Whereas for others 'Design goal, Actors map and Persona really helped us to get a clear vision of what we wanted to do and what we should have worked on. Anyway, the project deliverables demonstrate the participants culture sensitivity; they were able to distinguish the relevance of culture sensitivity in design from different angles and perspectives; cultural heritage, family culture, national cultures, subcultures such as tourists and taxi-drivers, and Kish island culture. Overall, learning new methods and tools appeared to be key for an overall positive experience of the design event. Also, learning a systematic approach, in which for example, ideation is postponed was often mentioned as valuable. But again, the most important and positive comments were about how the methods were taught, see Theme 2 .

\subsection{The experience of the course theme 'designing for cultures'}

Most of the participants appreciated the theme: 'Designing for cultures - How to be culture sensitive in design' and topic 'designing for Kish Island'. It met the expectations, and students saw the relevance of it: 'I am interested in the field of culture, today design is going to be more universal, so knowing about the cultural diversity is very important for designers' and students understood that culture is more than national differences: 'Tuning with our culture and understanding deep meaning of culture to correct interpretation of it'. Also, most of the participants liked the Kish Island context, because it was new to them and easy to explore. Although one of the participants did not like the island as a topic, because he expected to work on a topic related to the culture heritage of Iran, and this heritage is not strongly represented on the island. However, from the final results, discussions with participants, and questionnaire responses we conclude that most participants liked our comprehensive approach towards the concept of culture, including contemporary cultural practices, sub-cultures (e.g. regional culture, family culture), etcetera and, again especially the cultural encounters between participants and the teachers. 


\subsection{Overall conclusions and insights}

The results show that the international and intercultural workshops are perceived by students as fruitful and have an impact on design student's cultural sensitivity. It seems that the students focus and reflect not only on the value of the content and the outcome of the workshop, but also on the value of the international character of the event itself, of other being together and getting to know each other. This insight allows us to be aware of the importance of organising the social aspects of the workshops to enrich the experience. For both aspects, workshop content and social events, enough time needs to be allocated; the pressure cooker model is fruitful, but should not lead to too much intensity, stress and thereby a less rich learning experience.

Next, the student show that the workshop, although doable from a design perspective, is not an easy process: students have to get used to each other (dealing with sub-cultural variations) and to the cultural context they are working in, they have to understand their barriers and dilemmas, their misunderstandings and miscommunications. To achieve that, we identified that an important factor that supports the process of finding a common ground is the value of a positive attitude of the workshop facilitators: allowing students to make mistakes and embracing differences and misunderstandings as learning potentials.

The results of this study are limited by the fact that we only had the questionnaires to gather our data and insights. The answers to these questionnaires are influenced by some factors. First, we sent it out ourselves, which may limit the freedom of expression, to protect the relationship. Furthermore, this could exclude the ones that are negative. In depth interviews executed by an independent party would greatly improve the study. This study allows us to define which topics to zoom in on, during our next workshop evaluations.

\section{IMPLICATIONS FOR FUTURE WORKSHOPS}

Doing a survey one month after a workshop made us aware of the value of 'aftercare': it was meaningful to be in contact again with the students, to get a feel for the impact of the workshop after a while, and to get an insight in what has been learned and remembered. It seems that this survey in itself has value, to consolidate the impact. Also, in the future, we see the value of creating this opportunity to stay in contact with the content and results of the workshop and with each other, making sure that the lessons learned can be captured (on a website, booklet, card set etcetera). As one of the students commented: '...Something we would refer to in the future. Maybe a website dedicated to these workshops (synced with what instructors are teaching with details for each stage) where participants upload their materials through the workshop at each stage and the system automatically create the booklet and other materials for each team and participants can always go back to the website to review the process'.

\section{ACKNOWLEDGEMENTS}

The authors gratefully acknowledge Nasibeh Soltani (who asked us to bring our knowledge and experiences to Iran and who was one of the four teachers), and employees and students of Kish International Campus who were a great support in the organisation of the design event.

\section{REFERENCES}

[1] van Boeijen A.G.C., Sonneveld M.H. and Hao C. Culture sensitive design education - the best of all worlds. In proceedings Engineering and Product Design Education conference, 7-8 September 2017, Oslo, Norway.

[2] van Boeijen A.G.C. Crossing Cultural Chasms: Towards a culture-conscious approach to design. Doctoral Thesis, 2015, Delft University of Technology, Delft.

[3] Stafford J.R., Bowman R., Ewing T., Hanna J. and Lopez-De Fede A. (1997). Building Cultural Bridges. Bloomington: In: National Educational Service.

[4] Joy S. and Kolb D.A. Are there cultural differences in learning style? International Journal of Intercultural Relations, 2009, 33(1), 69-85.

[5] Bennett J.M. and Bennett M.J. Developing intercultural sensitivity: An integrative approach to global and domestic diversity. In D. Landis, J. Bennett \& M. Bennett (Eds.), Handbook of intercultural training (3rd ed, 2004, pp. 147-165). Thousand Oaks: Sage.

[6] Hao C., van Boeijen A.G.C. and Stappers P.J. Cultura: A communication toolkit for designers to gain empathic insights across cultural boundaries. In proceedings of IASDR conference 2017, 31 October-3 November 2017, Cincinnati, Ohio, United States. 